\title{
Fabrication and Characterization of Molecular Films of 11-Oxa[9]helicene and 9-Diethyleneglycoxy-11-oxa[9]helicene
}

\author{
Md Jalil Miah, Mohammad Shahabuddin, Md. Nazmul Kayes, Michinori Karikomi, \\ Eri Nasuno, Norihiro Kato, Ken-ichi Iimura* \\ Graduate School of Engineering, Utsunomiya University, \\ 7-1-2 Yoto, Utsunomiya, Tochigi, 321-8585, Japan. \\ * Corresponding author: Fax: 81-28-689-6172, e-mail: emlak@cc.utsunomiya-u.ac.jp
}

\begin{abstract}
A highly $\pi$-conjugated helical compound, 11-oxa[9] helicene $(\mathrm{O} 9 \mathrm{H})$, and its derivative 9-diethyleneglycoxy-11-oxa[9]helicene $(2 \mathrm{EO} 9 \mathrm{H})$ were used to prepare thin films by the Langmuir technique, and their structures and photoelectrochemical properties were evaluated. Brewster angle microscopic (BAM) observation implied that 2EO9H molecules formed a homogeneous, flat monolayer but $\mathrm{O} 9 \mathrm{H}$ molecules three-dimensionally aggregated at the air-water interface. The same morphological features were also observed for films deposited on silicon wafers using atomic force microscopy (AFM). The film structures on solid supports were estimated by X-ray reflectivity (XR) measurements. The XR fitting analysis and theoretical calculation suggested that in the 2EO9H monolayer the hydrophobic aromatic planes of helicene moiety oriented perpendicularly to the monolayer plane and the hydrophilic diethyleneglycoxy group (DEG) was bended/twisted. It was also indicated that optical band gaps estimated from $\mathrm{UV}$-visible spectra are not much changed due to introduction of DEG chain to the $\mathrm{O} 9 \mathrm{H}$ moiety, but the $2 \mathrm{EO} 9 \mathrm{H}$ monolayer showed larger photocurrent densities.
\end{abstract}

Key words: oxa[9]helicene, organic semiconductor, thin film, Langmuir technique, photocurrent

\section{INTRODUCTION}

Polyacenes have received much attention because of their unique electronic and geometrical structures. Especially, they have been attentively studied as semiconducting materials or active material in the plastic electronic devices such as organic light emitting diodes (OLEDs), thin film transistors, and photovoltaic devices, due to their large and extended $\pi$-conjugation systems which significantly enhanced carrier mobility [1]. Helicenes consist of ortho-fused helical aromatic rings $[2,3]$. Although helicene parts are twisted or noncoplanar, they show a tendency to stack in the face-toface manner in hexagonally packed columns to form a macroscopic liquid crystalline fiber [4a] or in the edge-to-edge fashion in parallel columns with exposing their edges to the surface [4b]. It was also observed that co-facial stacking of molecules with extended $\pi$-conjugated system rendered high carrier mobility by coupling of orbitals among the neighboring molecules [5, 6]. Thus, aggregation of highly fused conjugated geometry in a columnar fibrous crystal could provide an extended $\pi$-conjugation, which would optimize the efficiency and carrier-transport. Moreover, the non- linear or non-coplanar helical configuration of helicenes could prevent close packing interactions, thereby effectively relieving excited-state quenching [7]. These structural characteristics led the helicenes being comprehensively studied for exploiting in multiple applied fields, e.g., asymmetric catalysis [8], electro- luminescence [9], nonlinear optics [10], OLED [11,12], reversible sensor [12], and so on. A number of helicene and heterohelicene derivatives have been utilized as an efficient emissive material in OLED, but oxa[9] helicene $(\mathrm{O} 9 \mathrm{H})$ or its derivatives have been seldom reported.

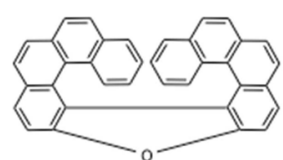

$\mathrm{O} 9 \mathrm{H}$

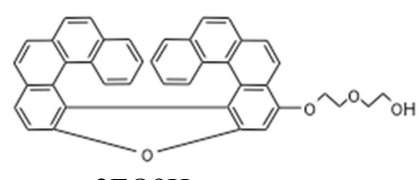

$2 \mathrm{EO} 9 \mathrm{H}$
Fig. 1: Molecular structures of 11-oxa[9]helicene (O9H) and 9-diethylene-11-oxa[9] helicene (2EO9H).

The backbone of oxa[9]helicenes consists of fused aromatic rings and causes poor solubility in polar and apolar solvents. It is found that doping approach is an effective tactic for improving device performance. However, to circumvent current leakage from the device, a homogeneous film without crumb boundaries or pinholes is essential [13]. To acquire this fact, the introduction of appropriate substituents into organic molecules is a prime approach, which could also guarantee the solubility of the molecules in many solvents for the development of devices in solution [14]. So, for the increase in solubility into a polar solvent and enhancement of surface immobilization, we introduced diethyleneglycol (DEG) group to the helicene moiety of O9H (Fig. 1). It was expected that this modification would also give amphiphilicity to the helicene and thus monomolecular arrangements would be achieved at the air-water interface using the Langmuir technique where the fine control of film structures such as thickness, molecular density, and orientation of molecules could be 
enabled [15]. In the present work, we applied the Langmuir technique to $\mathrm{O} 9 \mathrm{H}$ and $2 \mathrm{EO} 9 \mathrm{H}$, and resultant film morphology and structures were studied using BAM, AFM, and XR. Photoelectrochemical properties of the films were also evaluated to consider the semiconducting utility of $\mathrm{O} 9 \mathrm{H}$ and its derivative.

\section{EXPERIMENTAL}

The compounds $\mathrm{O} 9 \mathrm{H}$ and $2 \mathrm{EO} 9 \mathrm{H}$ were synthesized according to the procedure described in the literature [16]. ${ }^{1} \mathrm{H}$ and ${ }^{13} \mathrm{C}$ NMR spectra were collected on a Varian 500 NMR system. Fourier transform infrared spectra (FT-IR) were recorded on a FT/IR-420 (JASCO). High resolution mass spectra (HRMS) were obtained by JMS-777V (JEOL). The experimental results of 2EO9H were given below; Yellowish crystal, $\mathrm{mp}$ : 224-228 ${ }^{\circ} \mathrm{C}$. IR (KBr) 3421, 3042, 2869, 1578, 1284, 1087, $830 \mathrm{~cm}^{-1} .{ }^{1} \mathrm{H}$ NMR (500 MHz, $\left.\mathrm{CDCl}_{3}\right): \delta$ $8.47(1 \mathrm{H}, \mathrm{d}, J=8.5 \mathrm{~Hz}), 8.20(1 \mathrm{H}, \mathrm{d}, \quad J=8.5 \mathrm{~Hz}), 8.19$ $(1 \mathrm{H}, \mathrm{d}, J=8.5 \mathrm{~Hz}), 7.96(1 \mathrm{H}, \mathrm{d}, J=8.5 \mathrm{~Hz}), 7.67(1 \mathrm{H}$, s), $7.52-7.58(4 \mathrm{H}, \mathrm{m}), 7.36-7.39(2 \mathrm{H}, \mathrm{m}), 7.27-7.31$ $(2 \mathrm{H}, \mathrm{m}), 6.75(1 \mathrm{H}, \mathrm{t}, J=8.5 \mathrm{~Hz}), 6.74(1 \mathrm{H}, \mathrm{t}, J=8.5$ $\mathrm{Hz}), 6.30(1 \mathrm{H}, \mathrm{d}, J=8.5 \mathrm{~Hz}), 6.25(1 \mathrm{H}, \mathrm{d}, J=8.0 \mathrm{~Hz})$, $5.80(1 \mathrm{H}, \mathrm{t}, J=8.0 \mathrm{~Hz}), 5.73(1 \mathrm{H}, \mathrm{t}, J=8.0 \mathrm{~Hz}), 4.62-$ $4.65(2 \mathrm{H}, \mathrm{m}), 4.17(2 \mathrm{H}, \mathrm{t}, J=4.5 \mathrm{~Hz}), 3.77-3.82(4 \mathrm{H}$, m). ${ }^{13} \mathrm{C} \mathrm{NMR}\left(125 \mathrm{MHz}, \mathrm{CDCl}_{3}\right.$ ) $): \delta 155.27,155.02$, $154.04,130.66,130.04,129.83,129.82,129.78,127.68$, $127.62,127.37,127.04,126.74,126.67,126.49,126.48$, $126.40,126.28,125.55,125.52,125.42,125.40,125.02$, $124.92,124.79,124.24,124.21,124.18,122.45,122.37$, $122.03,121.66,120.13,115.08,110.85,92.02,72.99$, 70.05, 69.03, 62.18. HRMS (EI) Calcd. for $\mathrm{C}_{40} \mathrm{H}_{28} \mathrm{O}_{4}$, 572.1988, found: 572.1977 .

The ultrapure water was used for all experiments. A KSV minitrough system 2 was used for surface pressure $(\pi)$ - molecular area $(A)$ isotherm measurements and monolayer deposition. A NIMA trough 702 equipped with Nanofilm Technologie EP3-BAM was employed for BAM observation. A solution was spread at the airwater interface in a Langmuir trough at $24^{\circ} \mathrm{C}$. After 30 min from the spreading, the film was compressed at a rate of $10 \mathrm{~mm} \cdot \mathrm{min}^{-1}$. The film deposition was made at $10 \mathrm{mN} \cdot \mathrm{m}^{-1}$ by a horizontal scooping-up method [17] at deposition rate $1 \mathrm{~mm} \cdot \mathrm{min}^{-1}$. Solid substrates used were quartz glass slides (Pier Optics) for UV-visible spectroscopy, silicon wafers (MEMC) for AFM and XR experiments, and fluorine-doped tin oxide (FTO) coated glass slides (surface resistivity $\sim 7 \Omega /$ sq, Sigma-Aldrich) for photocurrent measurements. UV-visible spectra were measured using a Jasco V-670 UV/Vis/NIR spectrophotometer. AFM used was a Nanonavi II/E-sweep scanning probe microscope (Hitachi High-Tech Science) in dynamic force mode at room temperature in air with a silicon cantilever of rectangular tip. XR measurements were performed in a Rigaku SmartLab X-ray diffractometer with $9 \mathrm{~kW}$ rotating anode $\mathrm{CuK}_{\alpha}$ source and the fitting analysis was made using a Motofit package. Photocurrent measurements were performed in a three-electrode cell (a monolayer-deposited FTO as working electrode, a platinum counter electrode and $\mathrm{Ag} / \mathrm{Ag}^{+}$(3.0 $\mathrm{M} \mathrm{NaCl}_{\text {aq }}$ reference electrode) in a mixed electrolyte solution of $0.1 \mathrm{M} \mathrm{Na}_{2} \mathrm{SO}_{4}, 0.1 \mathrm{M} \mathrm{KH}_{2} \mathrm{PO}_{4}$ in an aqueous solution). A $0.1 \mathrm{M}$ methyl viologen solution was used as a supporting electrolyte at $\mathrm{pH}$ 5.9.

\section{RESULTS AND DISCUSSION}

Fig. 2 shows UV-visible absorption spectra of $\mathrm{O} 9 \mathrm{H}$ and $2 \mathrm{EO} 9 \mathrm{H}$ in chloroform solutions and in films deposited on quartz substrates. The absorption peaks appeared at $300-350 \mathrm{~nm}$ ascribed to a $\pi-\pi^{*}$ transition, which is archetypal to fused aromatic compounds $[11,12,18]$. The peaks at $380-430 \mathrm{~nm}$ would be attributed to the $n-\pi^{*}$ transition from oxygen atoms connecting to helicene rings $[18,19]$ and/or oxygen atom of ethylene glycol group [20]. Similar absorption behavior was found in the films except the corresponding bands were red-shifted to about $3-5 \mathrm{~nm}$. The shift would be caused by the $\pi$-stacking of the molecules on the solid film $[11,21,22]$. It is noted that the UV-visible spectra of both compounds in the solutions and in the films are almost similar and/or the degrees of red-shifts are also small, which might indicate that the stacking interaction is not so strong compared to typical planar aromatic molecules, because of helical and non-coplanar structure of the helicene molecule.

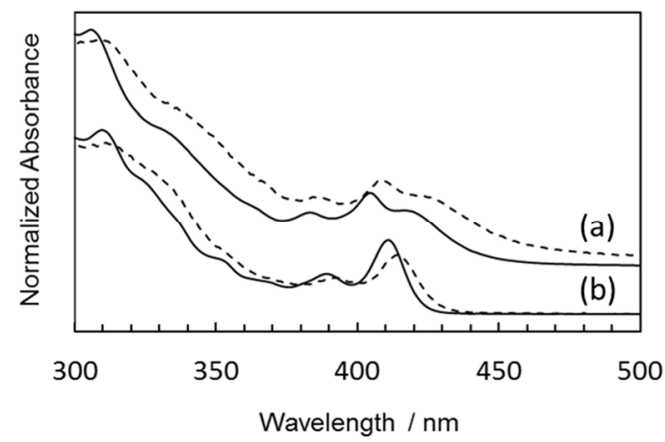

Fig. 2: UV-visible spectra of (a) $\mathrm{O} 9 \mathrm{H}$ and (b) 2EO9H in chloroform solutions (solid lines) and in films deposited on the quartz glasses (dotted lines).

When a molecule is irradiated with light of a specific wavelength, electron transition occurs from a lowenergy molecular orbital to a high-energy molecular orbital, which can be measured by UV-visible spectroscopy. An optical band gap of any organic molecules can easily be determined from UV-visible spectra according to an equation, $E_{\text {opt }}(\mathrm{eV})=h c / \lambda_{\text {onset }}$, where, $h$ is the plank constant, $c$ is the speed of light and $\lambda_{\text {onset }}$ is wavelength corresponds to the onset of absorption in a UV-visible spectrum [23]. From the UV-visible spectra (Fig. 2), it is found that the onsets of absorption for $\mathrm{O} 9 \mathrm{H}$ and $2 \mathrm{EO} 9 \mathrm{H}$ were 430 and $450 \mathrm{~nm}$, respectively. Thus, the optical band gaps calculated were $2.76 \mathrm{eV}$ for $\mathrm{O} 9 \mathrm{H}$ and $2.88 \mathrm{eV}$ for $2 \mathrm{EO} 9 \mathrm{H}$. These values are almost similar with each other and consistence with that previously reported for 9-tetraethyleneglycoxy-11-oxa[9]helicene [20].

The $\pi$ - $A$ isotherms measured for $\mathrm{O} 9 \mathrm{H}$ and $2 \mathrm{EO} 9 \mathrm{H}$ are presented in Fig. 3. The isotherm for $\mathrm{O} 9 \mathrm{H}$ displays sharp rise of surface pressure at around $20 \AA^{2} \cdot \mathrm{molec}^{-1}$. In the case of $2 \mathrm{EO} 9 \mathrm{H}$, the pressure increases monotonously upon compression up to the collapse of the monolayer at about $25 \mathrm{mN} \cdot \mathrm{m}^{-1}$. BAM images observed along with the isotherm measurements are shown in Fig. 4. On the water surface where the $\mathrm{O} 9 \mathrm{H}$ molecules were spread, significantly bright spots/regions were observed even before the surface pressure rise (image (a)), indicating that three dimensional aggregates were formed sponta- 
neously after the spreading of $\mathrm{O} 9 \mathrm{H}$ molecules on the water surface. This inability in forming monolayer is apparently due to less hydrophilicity of the $\mathrm{O} 9 \mathrm{H}$ molecule. On the other hand, in case of $2 \mathrm{EO} 9 \mathrm{H}, \mathrm{BAM}$ images indicate the formation of a monolayer; condensed-phase islands were coexist with a gaseous phase at $70 \AA^{2} \cdot$ molec $^{-1}$ (image (c)), and the area occupied by the gaseous phase decreased upon compression. Then the water surface was covered by the homogeneous condensed-phase monolayer (image (d)).

AFM topographic images of films transferred at 10 $\mathrm{mN} \cdot \mathrm{m}^{-1}$ on silicon wafers were shown in Fig. 5. One can see a very rough surface for the $\mathrm{O} 9 \mathrm{H}$ film surface (image (a)). The height difference between the top and bottom part of the image is more than ten $\mathrm{nm}$, suggesting the three-dimensional aggregation of the $\mathrm{O} 9 \mathrm{H}$ molecules. By contrast, the surface of $2 \mathrm{EO} 9 \mathrm{H}$ film (image (b)) is very homogeneous. These observations are consistent with the perception gained through BAM observation.

The XR fitting analysis was performed for the $2 \mathrm{EO} 9 \mathrm{H}$ monolayer transferred on the silicon wafer, in order to characterize the monolayer structure. The XR plot and a fitted curve for the 2EO9H monolayer are shown in Fig. 6 , and the fitting parameters are summarized in Table I.

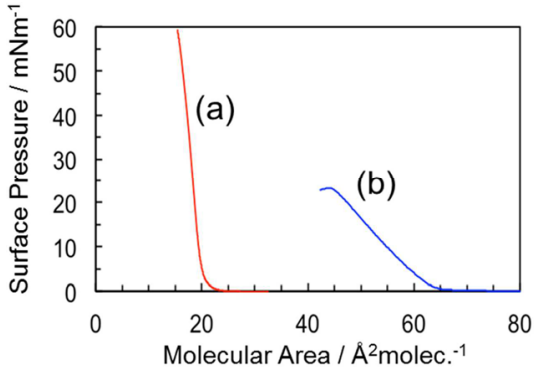

Fig. 3: $\pi-A$ isotherms for (a) $\mathrm{O} 9 \mathrm{H}$ and (b) $2 \mathrm{EO} 9 \mathrm{H}$.
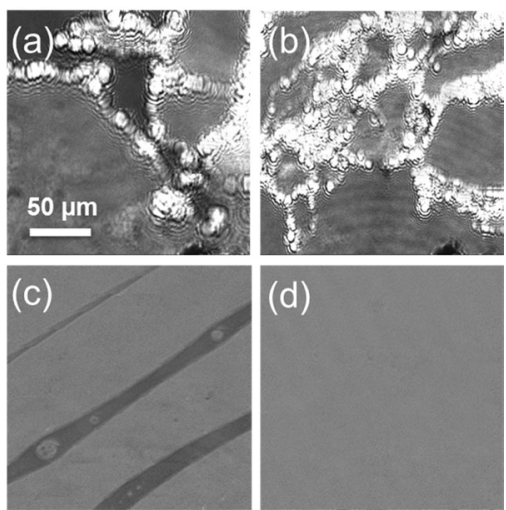

Fig. 4: BAM images of an $\mathrm{O} 9 \mathrm{H}$ film observed at (a) 30 and (b) $19 \AA^{2} \cdot$ molec. $^{-1}$ and of a $2 \mathrm{EO} 9 \mathrm{H}$ monolayer at (c) 70 and (d) $55 \AA^{2} \cdot$ molec. $^{-1}$.
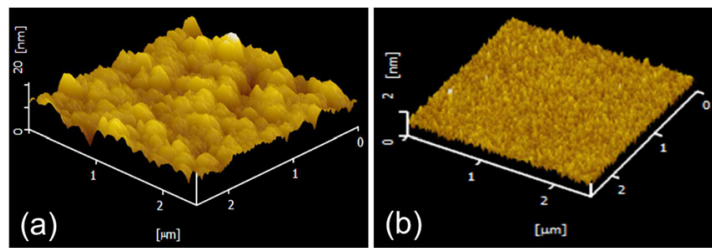

Fig. 5: AFM images of (a) $\mathrm{O} 9 \mathrm{H}$ and (b) $2 \mathrm{EO} 9 \mathrm{H}$ films transferred at $10 \mathrm{mN} \cdot \mathrm{m}^{-1}$ on silicon wafers.
The XR data could be fitted well by assuming the molecular conformation that the helicene rings are orientated perpendicularly with respect to the monolayer plane, whereas the DEG chain are twisted/bended. The length of helicene moiety obtained by the XR fitting analysis is $13.5 \AA$, which is close to the diameter (12 $\AA$ ) of helicene moiety calculated using Spartan 10 with geometrical optimization by molecular mechanics MMFF basis set in vacuum [20]. The vertical orientation of helicene rings accounts for the smaller molecular area in the condensed-phase region of $\pi-A$ isotherm, compared to the area of a helicene plane (ca. $113 \AA^{2}$ ) calculated from the theoretical diameter.

The number of electrons $(\mathrm{Ne})$ for the helicene moiety is calculated to be 242 , using the electron density and the thickness $(d)$ from the XR analysis and the molecular area $(A)$ from the $\pi-A$ isotherm. This value is coincident with that theoretically estimated from the molecular structure. On the other hand, the $\mathrm{Ne}$ for the DEG chain is calculated to be 76 . This value is higher than that of theoretical one, which would be due to hydration of water molecules to the DEG chain.

Because helicenes are expected to have semiconductive properties as mentioned above, the photocurrent response of the films deposited on FTO substrates was measured with a three-electrode cell system (Fig.7). It was observed that the photocurrent generated by a bare FTO substrate under the illumination of light (xenon lamp) was negligible. For both of the $\mathrm{O} 9 \mathrm{H}$ and $2 \mathrm{EO} 9 \mathrm{H}$ films deposited on the FTO substrate, the photocurrent was generated when the light source was turned on. It is difficult to compare the photocurrent densities between

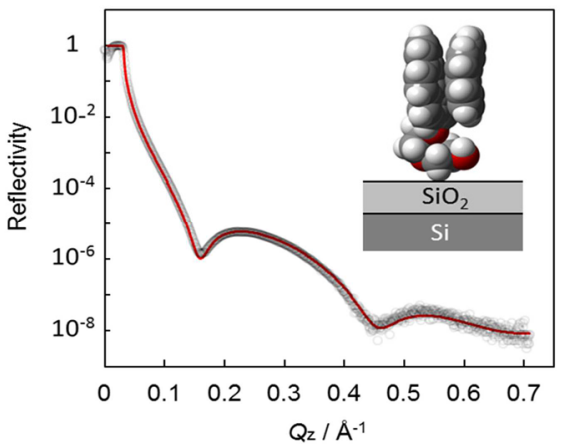

Fig. 6: XR data (circles) and a fitted curve (solid line) for the $2 \mathrm{EO} 9 \mathrm{H}$ monolayer transferred at 10 $\mathrm{mN} \cdot \mathrm{m}^{-1}$ on a silicon wafer. The inset is a spacefilling model of $2 \mathrm{EO} 9 \mathrm{H}$ molecule having helicene rings vertically orientated with respect to the monolayer plane and a twisted/bended DEG chain, suggested by XR curve fitting analysis.

Table I: Thickness $(d)$, roughness $(\sigma)$, and electron density $(\rho)$ for the $2 \mathrm{EO} 9 \mathrm{H}$ monolayer on the silicon wafer, determined by XR curve fitting analysis.

\begin{tabular}{ccccc}
\hline \multicolumn{2}{c}{ Layer } & $d / \AA$ & $\sigma / \AA$ & $\rho / \AA^{-3}$ \\
\hline \multirow{2}{*}{ Monolayer } & Helicene & $13.5 \pm 0.2$ & $3.4 \pm 0.2$ & 0.327 \\
& DEG & $4.2 \pm 0.1$ & $3.2 \pm 0.2$ & 0.340 \\
\hline \multirow{2}{*}{ Substrate } & $\mathrm{SiO}_{2}$ & $3.8 \pm 0.1$ & $3.9 \pm 0.1$ & 0.671 \\
& $\mathrm{Si}$ & - & $2.0 \pm 0.1$ & 0.713 \\
\hline
\end{tabular}


the $\mathrm{O} 9 \mathrm{H}$ film and the $2 \mathrm{EO} 9 \mathrm{H}$ monolayer because the $\mathrm{O} 9 \mathrm{H}$ molecules form undefined aggregates. However, taking into account the difference in molecular area at the deposition pressure, the result in Fig. 7 could be interpreted as that the photocurrent density is not simply proportional to the molecular density on the substrates. This insight indicates several possibilities to improve the photocurrent generation properties of thin films at the interfaces, for example, a certain degree of ordered arrangement of film molecules may be necessary for efficient generation of photocurrents, or the electron donating nature of ethylene oxide (EO) group efficiently worked to increase electron density in the $\pi$-cloud of helicene moiety [24, 25], and so on. Further studies are now under progress using oxa[9] helicene derivatives with the different number of EO units.

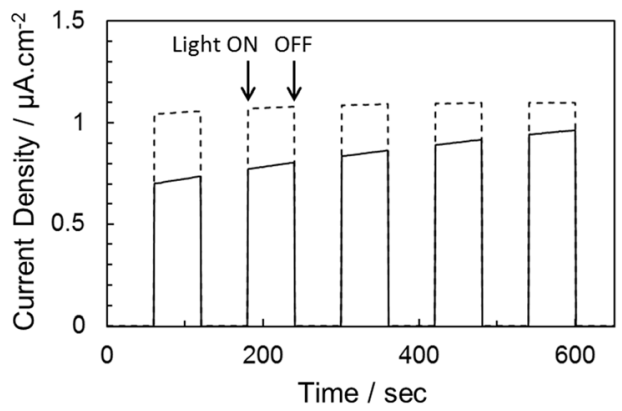

Fig. 7: Photoresponse of the O9H film (solid line) and the $2 \mathrm{EO} 9 \mathrm{H}$ monolayer (dotted line) transferred at $10 \mathrm{mN} \cdot \mathrm{m}^{-1}$ on FTO substrates.

\section{CONCLUSIONS}

It was shown that a novel oxa[9] helicene derivative with hydrophilic DEG chain, 2EO9H, has amphiphilic characteristics and thus forms the homogeneous, flat Langmuir monolayer at the air-water interface, while the mother compound $\mathrm{O} 9 \mathrm{H}$ aggregates three-dimensionally on the water surface due to the less hydrophilicity. The layer structure of the 2EO9H monolayer transferred on the silicon wafer was analyzed using the XR technique along with theoretical calculation of optimized molecular structure. All the results revealed that $2 \mathrm{EO} 9 \mathrm{H}$ forms monomolecular layer where the aromatic helicene planes are stacked with the orientation perpendicular to the monolayer surface. The photocurrent response evolution shows that the monolayer of $2 \mathrm{EO} 9 \mathrm{H}$ provides better photocurrent density than the three-dimensional aggregates of $\mathrm{O} 9 \mathrm{H}$ despite the amount of molecules deposited on the FTO substrates was larger for the $\mathrm{O} 9 \mathrm{H}$ film. Researches have been progressing in order to clarify the effect of the number of hydrophilic EO units to the film formability and photoelectrochemical properties.

\section{Acknowledgement}

Authors appreciate to Dr. Masaaki Tomura (Institute for Molecular Science, Japan) for HRMS measurements. M. Jalil Miah, M. Shahabuddin and M. N. Kayes are very grateful to the Ministry of Education, Culture, Sports, Science, and Technology (MEXT) of the Japanese Government for the fruitful scholarship.

References

[1] J. E. Anthony, Chem. Rev., 106, 5028-5048 (2006).
[2] R. H. Martin, Angew. Chem., Int. Ed. 13, 649-660 (1974).

[3] S. D. Han, D. R. Anderson, A. D. Bond, H. V. Chu, R. L. Disch, D. Holmes, J. M. Schulman, S. J. Teat, K. P. C. Vollhardt, G. D. Whitener, Angew. Chem., Int. Ed., 41, 3227-3230 (2002).

[4] (a) A. J. Lovinger, C. Nuckolls, T. J. Katz, J. Am. Chem. Soc., 120, 264-268 (1998). (b) C. Nuckolls, J. Katz, T. Verbiest, S. V. Elshocht, H. G. Kuball, S. Kiesewalter, A. J. Lovinger, A. Persoons, J. Am. Chem. Soc., 120, 8656-8660 (1998).

[5] J. E. Field, G. Muller, J. P. Riehl, D. Venkataraman, $J$. Am. Chem. Soc., 125, 11808-11809 (2003).

[6] Y. Tang, T. A. Cook, A. E. Cohen, J. Phys. Chem. A, 113, 6213-6216 (2009).

[7] L.Shi, Z.Liu, G.Dong, L.Duan, Y.Qiu, J.Jia, W.Guo, D Zhao, D. Cui, X. Tao, Chem.Eur.J., 18,8092-8099 (2012).

[8] M. T. Reetz, E. W. Beuttenmuller, R. Goddard, Tetrahedron Lett., 38, 3211-3214 (1997).

[9] Y. Ooyama, G. Ito, H. Fukuoka, T. Nagano, Y. Kagawa, I. Imae, K. Komaguchi, Y. Harima, Tetrahedron, 66, 7268-7271 (2010).

[10] A. Bossi, E. Licandro, S. Maiorana, C. Rigamonti, S. Righetto, G. R. Stephenson, M. Spassova, E. Botek, B. Champagne, J. Phys. Chem. C, 112, 7900-7907 (2008).

[11] S. Sahasithiwat, T. Mophuang, L. Menbangpung, S. Kamtonwong, T. Sooksimuang, Synth. Met., 160, 11481152 (2010)

[12] J. Storch, J. Zadny, T. Strasak, M. Kubala, J. Sykora, M. Dusek, V. Cirkva, P. Matejka, M. Krbal, J. Vacek, Chem. Eur. J., 21, 2343-2347 (2015).

[13] M. Zhu, T. Ye, C. G. Li, X. Cao, C. Zhong, D. Ma, J. Qin, C. Yang, J. Phys. Chem. C, 115, 17965-17972 (2011).

[14] M.S. Sonar, Y.H. Soh, J.T. Chen, A. Henssler, A. Sellinger, Sellinger, Org. Lett., 12, 3292-3295 (2010).

[15] K. Iimura, T. Kato, Langmuir-Blodgett (LB) Film, in K. Ariga ed., Organized Organic Ultrathin Films: Fundamentals and Applications, pp.43-105, Wiley- VCH (2012).

[16] (a) M. Karikomi, M. Yamada, Y. Ogawa, H. Houjou, K. Seki, K. Hiratani, K. Haga, T. Uyehara, Tetrahedron Lett., 46, 5867-5869 (2005). (b) M. Salim, H. Ubukata, T. Kimura, M. Karikomi, Tetrahedron Lett., 52, 6591-6593 (2011).

[17] T. Kato, N. Matsumoto, M. Kawano, N. Suzuki, T. Araki and K. Iriyama, Thin Solid Films, 242, 223-228 (1994).

[18] Y. Takeda, M. Okazaki, Y. Maruoka and S. Minakata, Beilstein J. Org. Chem., 11, 9-15 (2015).

[19] C. G. Claessens, G. D. Rodriguez and T. Torres, Chem. Rev., 102, 835-853 (2002).

[20] M. Jalil Miah, M. Shahabuddin, M. Karikomi, M. Salim, E. Nasuno, N. Kato, K. Iimura, Accepted in Bull Chem. Soc. Jpn.

[21] J. Y. Shane and T. M. Swager, J. Am. Chem. Soc., 120, 5321-5322 (1998).

[22] C. Kim, T. J. Marks, A. Facchetti, M. Schiavo, A. Bossi, S. Maiorana, E. Licandro, F. Todescato, S. Toffanin, M. Muccini, C. Graiff and A. Tiripicchio, Org. Electron., 10, 1511-1520 (2009).

[23] M. M. Ahmida and S. H. Eichborn, ECS Trans., 25, $1-10(2010)$.

[24] J. Xu, G. Nie, S. Zhang, X. Han, S. Pu, L. Shen and O. Xiao, Eur. Polym. J., 41, 1654-1661 (2005).

[25] M. Rancic, N. Trisovic, M. Milcic, G. Uscumlic and A. Marinkovic, Spectrochim. Acta, Part A, 86, 500-507 (2012).

(Received November 19, 2015; Accepted November 29, 2015) 